Review

\title{
The Cardiovascular System in Heat Stroke
}

\author{
Miles Marchand, MD, and Kenneth Gin, MD, FRCPC, FCCS ${ }^{a, b}$ \\ ${ }^{a}$ Division of Cardiology, University of British Columbia, Vancouver, British Columbia, Canada \\ ${ }^{b}$ Centre for Cardiovascular Innovation, University of British Columbia, Vancouver, British Columbia, Canada
}

\begin{abstract}
In June 2021, western Canada experienced an unprecedented heat wave, breaking dozens of temperature records. As a result, the region had a significant uptick in sudden deaths, emergency department visits, and hospital admissions. Under thermal stress, the human body achieves heat dissipation through evaporation of sweat and increased cutaneous blood flow. When these mechanisms are overwhelmed, the core body temperature rises, which leads to heat stroke, a lifethreatening syndrome of hyperthermia and central nervous system dysfunction in the setting of an environmental thermal load. Heat dissipation relies on an intact cardiovascular system to dilate cutaneous vasculature and increase cardiac output. Individuals with
\end{abstract}

In June 2021, western Canada experienced an unprecedented heat wave, setting dozens of weather records, including a new all-time Canadian temperature record of $49.6^{\circ} \mathrm{C}$ in the village of Lytton, British Columbia. This heat wave led to an almost fourfold spike in sudden deaths, as well as significant increases in emergency calls and hospital visits, putting a strain on the Canadian healthcare system. ${ }^{1}$ Preliminary reports from the British Columbia Coroner's Service suggest that the majority of the reported deaths were in elderly individuals. ${ }^{2}$

Temperatures are on the rise worldwide, with the mean global temperature $0.99^{\circ} \mathrm{C}$ hotter in the first 2 decades of the 21 st century compared to that from $1850-1900 .^{3}$ In Canada, the rate of temperature rise is approximately twice the global rate. ${ }^{4}$ In fact, from 1948 to 2020, annual average temperatures in Canada increased by $1.8^{\circ} \mathrm{C}$. As temperatures rise, the frequency, severity, and duration of heat waves rise in parallel. ${ }^{5}$ Although humans are able to adapt to gradual increases in mean temperatures over time, heat waves, defined as prolonged periods of higher-than-normal temperatures, put an increased strain on the cardiovascular system. This strain may be further exacerbated by air pollution, ${ }^{6}$ which can be the result of

Received for publication August 31, 2021. Accepted October 4, 2021.

Ethics Statement: No ethics approval was required.

Corresponding author: Dr Miles Marchand, Gordon \& Leslie Diamond Health Care Centre, DHCC 9th Floor, 2775 Laurel St, Vancouver, British Columbia V5Z 1M9, Canada. Tel.: +1-604-875-4111.

E-mail: miles.marchand@alumni.ubc.ca

See page 162 for disclosure information.

\section{RÉSUMÉ}

En juin 2021, l'Ouest canadien a connu une vague de chaleur sans précédent, au cours de laquelle des dizaines de records de température ont été battus. La région a de ce fait connu une augmentation significative des morts subites, des consultations aux urgences et des hospitalisations. En cas de stress thermique, le corps humain dissipe la chaleur par l'évaporation de la sueur et l'augmentation du flux sanguin cutané. Lorsque ces mécanismes sont dépassés, la température corporelle centrale augmente ce qui entraîne un coup de chaleur, un syndrome potentiellement mortel associant une hyperthermie et une dysfonction du système nerveux central dans un contexte de charge thermique exogène. La dissipation de la chaleur

concurrent wildfires or smog. In countries such as Canada, where people and healthcare systems are not acclimatized to extreme heat, patients with underlying cardiovascular disease and other chronic diseases are at heightened risk of developing heat stroke and its complications. Box 1 illustrates a clinical case that may be encountered during a heat wave. This review summarizes the current knowledge on the interaction between cardiovascular disease and heat stroke (Fig. 1).

\section{Definitions}

Heat stroke is a syndrome of hyperthermia (usually a body temperature of $>40.5^{\circ} \mathrm{C}$ ) secondary to extreme environmental heat exposure, with associated central nervous system dysfunction, with manifestations that can range from confusion to seizure to coma. ${ }^{7}$ Classic (non-exertional) heat stroke typically affects older individuals and those with underlying chronic diseases that impair the body's ability to dissipate heat. Conversely, exertional heat stroke typically affects younger individuals, most commonly athletes, outdoor workers, and military personnel, whose production of heat due to exertion overwhelms the body's ability to dissipate it. The incidence of classic heat stroke tends to spike during heat waves, whereas exertional heat stroke occurs sporadically at any time of year. This review focuses on classic heat stroke, as it is more closely associated with cardiovascular function.

\section{Pathophysiology of Heat Stroke}

Heat stroke results from an imbalance in heat production and heat dissipation. When thermal homeostasis is 
impaired cardiovascular function have a limited ability to increase stroke volume, cardiac output, and blood flow to the skin, increasing the risk of heat stroke. In turn, these patients, whose cardiac condition is already compromised, are susceptible to cardiovascular complications of heat stroke, including arrhythmias, myocardial ischemia, heart failure, shock, and sudden death. Indeed, the majority of excess deaths during heat waves are cardiovascular in origin, highlighting the impact the cardiovascular system has on the development of heat stroke, and vice versa. This review summarizes the current understanding of the interaction between the cardiovascular system and heat stroke, including the pathophysiology, cardiovascular complications, and treatment. maintained, heat production is dictated by the body's metabolic rate, and heat dissipation is achieved through 4 major mechanisms-evaporation of sweat, convection, conduction, and radiation. The latter 3 mechanisms are achieved through passive transfer of heat from the skin to the environment, and they are regulated through cardiac output and cutaneous vascular tone. As core temperature rises, sweat production and cardiac output increase and blood flow is diverted to the skin through cutaneous vasodilation and visceral vasoconstriction.

Under an extreme environmental heat load, heat production increases through an increased metabolic rate, but the ability to dissipate heat decreases, due to a lower temperature gradient between the body and the environment. Indeed, as the environmental temperature exceeds the core body temperature, mechanisms of conduction, convection, and radiation act in reverse, with heat transferring from the environment to the body. Humid conditions can further exacerbate this heat imbalance, impairing the ability of sweat to evaporate. As heat production exceeds heat dissipation, the core body temperature rises. Cutaneous blood vessels maximally dilate, and fluid is lost through tachypnea, sweat production, and cutaneous blood flow. The resulting vasodilatory and hypovolemic state requires increased cardiac output to maintain mean arterial pressure; as this compensatory measure fails, circulatory collapse ensues, leading to a further rise in core body temperature.

On a molecular level, the body's initial adaptive response to a rise in core body temperature is a cytokine cascade, including release of heat-shock proteins, to protect against cellular damage ${ }^{8}$; however, prolonged/extreme hyperthermia results in a deleterious systemic inflammatory response due to heat-related cellular damage and possibly increased gastrointestinal permeability to endotoxins. ${ }^{7,9}$ This inflammatory response further exacerbates an already hypovolemic and distributive state, resulting in multiorgan dysfunction and death (Table 1).

\section{Impact of the Cardiovascular System on Heat Stroke}

Individuals with cardiovascular dysfunction, particularly the elderly, are unable to sufficiently augment cardiac output and increase cutaneous blood flow, and thus they have a repose sur la dilatation des vaisseaux sanguins cutanés et l'augmentation du débit cardiaque qui sont possibles lorsque le système cardiovasculaire est intact. Chez les personnes atteintes d'insuffisance cardiovasculaire, la capacité à augmenter le volume d'éjection, le débit cardiaque et le flux sanguin vers la peau est limitée, ce qui augmente le risque de coup de chaleur. Ainsi, ces patients dont la santé cardiaque est déjà compromise sont sensibles aux complications cardiovasculaires du coup de chaleur, dont les arythmies, l'ischémie myocardique, l'insuffisance cardiaque, l'état de choc et la mort subite. En effet, la surmortalité observée durant les vagues de chaleur est principalement d'origine cardiovasculaire, ce qui met en lumière l'effet du système cardiovasculaire sur la survenue des coups de chaleur, et vice versa. Le présent article résume la compréhension actuelle de l'interaction entre le système cardiovasculaire et le coup de chaleur, notamment pour ce qui est de la physiopathologie, des complications cardiovasculaires et des traitements.

heightened risk of developing heat stroke. Indeed, in a metaanalysis of heat stroke patients, underlying cardiovascular disease significantly increased the risk of death by almost 2.5 times. $^{10}$

The hypovolemia and decreased systemic vascular resistance caused by a thermal load require an increase in cardiac output to maintain blood pressure, organ perfusion, and thermal homeostasis. In healthy individuals subjected to a thermal stress, cardiac output increases, cutaneous vessels dilate, and splanchnic vessels constrict, resulting in maintenance of blood pressure and increased cutaneous blood flow. ${ }^{11}$ In contrast, older individuals have an attenuated ability to increase cardiac output, which is largely driven by an increase in heart rate, as opposed to stroke volume. Older individuals also have impaired cutaneous vasodilation, as a result of atherosclerotic disease and stiff vasculature that is less responsive to nitric oxide. ${ }^{12}$ Individuals with underlying ventricular dysfunction or stenotic valvular lesions are also unable to sufficiently augment cardiac output, increasing the risk of heat stroke and circulatory collapse. ${ }^{13,14}$ For example, in patients with mitral stenosis subjected to a thermal stress, hemodynamic studies demonstrate an impaired ability to increase cardiac output and stroke volume, and a significant increase in the pulmonary wedge pressure. ${ }^{14}$

\section{Box 1. Illustrative case problem}

During a heat wave in western Canada with temperatures $>40^{\circ} \mathrm{C}$ for 5 consecutive days, a 74 -year-old man living alone was taken to a hospital by ambulance after being found in his home with an altered level of consciousness. His past medical history included hypertension, type 2 diabetes mellitus, heart failure with preserved ejection fraction, and mild cognitive impairment. His rectal temperature was $41^{\circ} \mathrm{C}$, heart rate 126 beats per minute, blood pressure $94 / 56 \mathrm{~mm} \mathrm{Hg}$, respiratory rate 28 , and oxygen saturation $92 \%$ while breathing room air. His Glasgow coma scale (GCS) score was 6. An initial electrocardiogram demonstrated atrial fibrillation with rapid ventricular response, and $1 \mathrm{~mm}$ of ST-segment depressions in the inferior leads. His initial troponin I level was elevated at $1.344 \mathrm{ng} / \mathrm{L}$. 


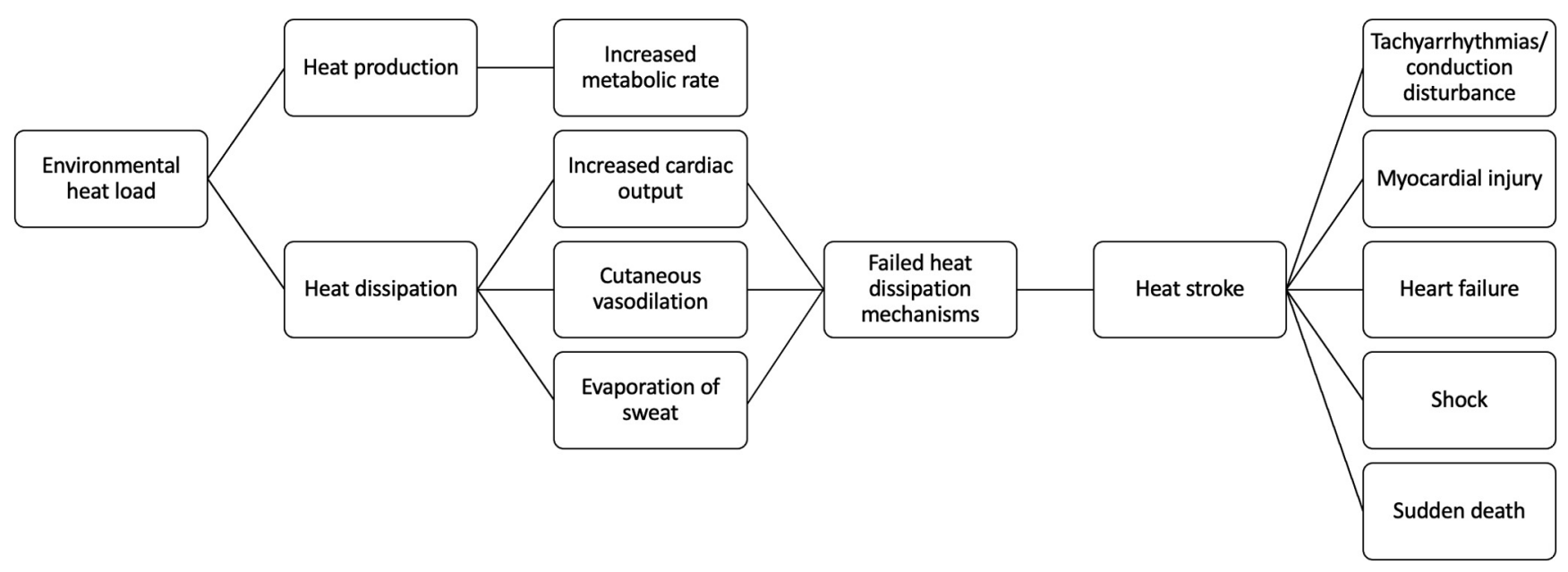

Figure 1. The cardiovascular system and heat stroke.

\section{Impact of Cardiac Medications on Heat Stroke}

A number of commonly prescribed cardiac medications increase the risk of heat stroke. Beta-blockers and nondihydropyridine calcium-channel blockers impair the ability to increase cardiac output in response to thermal stress. Diuretics exacerbate the hypovolemic state of heat stroke and increase the risk of electrolyte disturbances. Renin-angiotensin system inhibitors (angiotensin-converting enzyme inhibitors and angiotensin receptor blockers) increase the risk of acute kidney injury associated with heat stroke. Oral hypoglycemic agents (metformin, sulfonylureas, sodium-glucose cotransporter 2 [SGLT2] inhibitors) can also have deleterious effects in the setting of dehydration.

Although salicylates are recognized as anti-pyretic medications in the management of fever, this is accomplished through modulation of the hypothalamic temperature set point. Unlike fever, hyperthermia in heat stroke is not caused by hypothalamic dysfunction, and thus antipyretics, such as aspirin, have no benefit, and in fact, can worsen associated coagulopathy and liver dysfunction. ${ }^{15}$

\section{Impact of Heat Stroke on the Cardiovascular System}

Heat stroke increases the stress on the heart dramatically. In patients with underlying cardiovascular disease, the heart's ability to meet the heat-dissipation needs of the body can be overwhelmed, resulting in a number of cardiac complications (Table 2).

Table 1. Noncardiac manifestations of heat stroke

\begin{tabular}{lc}
\hline \hline Organ system & Manifestations in heat stroke \\
\hline $\begin{array}{l}\text { Central nervous } \\
\text { Respiratory }\end{array}$ & Confusion, seizure, coma \\
& Cardiogenic or noncardiogenic \\
pulmonary edema, ARDS \\
Hepatic & Liver-enzyme elevation, acute liver \\
& failure \\
Renal & Acute kidney injury, acid-base \\
& disturbances, electrolyte \\
Hematologic & disturbances \\
Musculoskeletal & DIC \\
\hline
\end{tabular}

ARDS, acute respiratory distress syndrome; DIC, disseminated intravascular coagulation.

\section{Arrhythmias}

One of the earliest and most common cardiac manifestations of heat stroke is sinus tachycardia, ${ }^{16,17}$ likely in response to volume depletion and adrenergic stimulation. Sinus tachycardia is also a key mechanism for heat dissipation through cardiac output augmentation. Other tachyarrhythmias, including atrial fibrillation and supraventricular tachycardia, are also common, and although they may be driven by the same underlying mechanisms as sinus tachycardia, they have deleterious effects on cardiac output. In the most severe cases, heat stroke can lead to ventricular tachyarrhythmias and cardiac arrest. ${ }^{18}$ Conduction disturbances, including PR prolongation, intraventricular conduction delay, and right and left bundle branch blocks can also occur, potentially as a result of rate-related aberrant conduction. QT prolongation is common, and may be associated with underlying electrolyte disturbances.

\section{Myocardial injury/ischemia}

Up to $50 \%$ of patients with heat stroke have ST-segment deviations. Although some of these changes are nonspecific,

Table 2. Cardiac manifestations of heat stroke

\begin{tabular}{lc}
\hline \hline Category & Manifestations in heat stroke \\
\hline Tachyarrhythmias & Sinus tachycardia, atrial fibrillation, \\
Conduction system impairment & SVT \\
& PR-interval prolongation, \\
& intraventricular conduction delay, \\
& LBBB, RBBB, QT-interval \\
& prolongation \\
Ischemic changes & Nonspecific ST and T wave changes, \\
& ischemic ST depressions or \\
& elevations, troponin elevation, \\
& regional wall-motion abnormalities \\
Myocardial impairment & Congestive heart failure, stress-induced \\
& cardiomyopathy, cardiogenic shock \\
Vascular/hemodynamic changes & Decreased SVR*, hypotension, \\
& decreased CVP \\
\hline
\end{tabular}

CVP, central venous pressure; LBBB, left bundle branch block; RBBB, right bundle branch block; SVR, systemic vascular resistance, SVT, supraventricular tachycardia.

${ }^{*}$ In severe cases in which patients develop a hypodynamic state, SVR can increase. 


\section{Box 2. Illustrative case conclusion}

The patient was immediately intubated for airway protection, and rapid cooling measures were initiated with cooled intravenous fluid resuscitation, application of ice packs, and fanning, with a target temperature of $<39^{\circ} \mathrm{C}$ achieved within 30 minutes. His home medications were reviewed, and his angiotensin-converting enzyme inhibitor and sodium-glucose co-transporter 2 inhibitor were withheld. Three hours later, he was responding to commands and was successfully extubated in the emergency department. His repeat troponin I level was $2.021 \mathrm{ng} / \mathrm{L}$. His echocardiogram was unchanged from baseline, with an ejection fraction of $50 \%$ and moderate diastolic dysfunction. The next day, he underwent a coronary angiogram, which demonstrated nonobstructive coronary artery disease. Prior to discharge, he returned to normal sinus rhythm, and his home medications were reinitiated. In the event of a future heat wave, he was advised to wear light clothing, seek refuge in an air-conditioned building, and stop taking his angiotensin-converting enzyme inhibitor and sodium-glucose cotransporter 2 inhibitor. His family was also advised to check on him regularly.

as many as half are consistent with ischemia (ST deviations in 2 or more contiguous leads) and are often associated with cardiac enzyme elevation and/or regional wall-motion abnormalities. ${ }^{16,17,19,20}$ In fact, in a study of 51 pilgrims suffering from heat stroke during the Hajj pilgrimage in Mecca, Saudi Arabia, $18 \%$ were found to have regional wall-motion abnormalities. ${ }^{19}$

Patients with elevated cardiac biomarkers, especially when these are at severe levels, have a significantly increased mortality rate. ${ }^{20,21}$ In a post hoc analysis of heat stroke patients during the 2003 Paris heat wave, 35\% of patients presenting with heat stroke had a troponin I test ordered, and of those patients, 32\% had moderate elevations, and 19\% had severe elevations. ${ }^{20}$ Those with severe troponin elevation had a $24 \%$ 1 -year survival rate, compared to $58 \%$ in patients with a normal troponin level.

Data on coronary angiography in heat stroke are limited. Chen et al. reported a case of a 39-year-old man with exertional heat stroke, troponin elevation, and anterolateral ST elevation who had patent coronary arteries on coronary angiography and was diagnosed with stress-induced cardiomyopathy. ${ }^{22}$ Beyond this report, no robust studies have explored coronary angiography in heat stroke patients who have ST deviations or troponin elevations.

The pathophysiology of ischemia in heat stroke is multifactorial. First, the majority of patients with heat stroke are elderly and have underlying cardiovascular dysfunction, including ventricular hypertrophy, valvular heart disease, and coronary artery disease; they are thus more susceptible to ischemia through supply-demand mismatch. Indeed, in an observational study by Mimish in 2012, 4 of 9 heat stroke patients with ischemic electrocardiographic changes had underlying left ventricular hypertrophy. ${ }^{17}$ Under thermal stress, increased cardiac output demands and dehydration further exacerbate the supplydemand mismatch. Cytotoxic effects from extreme hyperthermia may also play a role.

\section{Heart failure}

Heat stroke can also cause heart failure, which may be a result of ischemia and supply-demand mismatch, as well as stress-induced cardiomyopathy ${ }^{22}$ from the high adrenergic state of heat stroke. In healthy individuals, a thermal load results in a hyperdynamic left ventricle. For the majority of patients who experience circulatory collapse, it is related to distributive/hypovolemic shock, with a low systemic vascular resistance and high cardiac index; however, a minority of patients develop a hypodynamic state, with a reduced cardiac index and increased systemic vascular resistance, particularly those with pre-existing cardiovascular disease who are exposed to a heat wave for a prolonged period of time. ${ }^{10,23,24}$ Those with a hypodynamic state have an increased mortality rate. ${ }^{23}$

\section{Sudden death}

Heat waves result in increased incidence of sudden death, which often occurs before patients arrive in the hospital. The majority of deaths during heat waves are not directly attributuble to heat, but rather to underlying cardiovascular dysfunction. In fact, during the 1995 Chicago heat wave, an average of 241 excess deaths occurred per day, $94 \%$ of which were attributed to an underlying cardiovascular cause. ${ }^{25}$

\section{Treatment}

Rapid cooling to a target temperature of $<39^{\circ} \mathrm{C}$ is paramount for management of heat stroke, and such treatment should be delayed only if cardiopulmonary resuscitation is required. ${ }^{7,26,27}$ Patients presenting with coma or shock often also require intubation and mechanical ventilation for airway protection. Cooling can be achieved through a number of approaches, including cold water immersion, infusion of cold intravenous fluids, application of ice packs, and fanning. Theoretically, use of extracorporeal membrane oxygenation (ECMO) provides benefit, albeit no robust evidence supports its use. Cooling alone can rapidly reverse coma and other organ dysfunction associated with heat stroke, but serial biochemical monitoring of cardiac, hematologic, renal, and hepatic function is still warranted.

Cardiac evaluation, including continuous telemetry, echocardiography, and invasive hemodynamic monitoring also may be utilized. A mean arterial pressure of $>65 \mathrm{~mm} \mathrm{Hg}$ should be maintained, and this may require vasopressor support in addition to intravenous fluid resuscitation. In patients with heart failure, inotropic support can also be considered. No pharmacologic therapy has proven benefit in management of heat stroke; however, nonessential medications that may exacerbate heat stroke, such as diuretics, renin-angiotensin system inhibitors, and sodium-glucose co-transporter 2 (SGLT2) inhibitors should be withheld if there are no contraindications to doing so.

No evidence is available to guide management of patients with evidence of myocardial injury in the setting of heat stroke. Investigation and intervention in patients with evidence of myocardial ischemia should be based on a patient's underlying cardiac risk factors, ischemic symptoms, electrocardiographic changes, and troponin kinetics, with recognition that supply-demand mismatch (as opposed to acute plaque rupture) is the predominant pathophysiologic mechanism underlying myocardial injury in this population. 


\section{Prevention}

During heat waves, at-risk patients should be advised of strategies to mitigate the risk of heat stroke. Wearing light clothing and keeping well-hydrated is advised. When the ambient temperature surpasses the core body temperature, fanning is ineffective, as it simply recirculates hot air. When combined with a cool shower or bath, however, fanning is more effective. If air conditioning is not available in residences, malls, grocery stores, and hotels are alternative locations where people can find refuge from heat waves. Several Canadian provinces have established cooling centres that are activated during heat waves, a practice that has long been established in hotter countries, such as Saudi Arabia. Medications that may exacerbate heat stroke can be proactively withheld during severe heat waves, especially in vulnerable patients who may not be able to adhere to other preventive measures. Family members, neighbours, and community members should be encouraged to check on at-risk individuals frequently. Please see Box 2 for a conclusion to the illustrative case presented in Box 1.

\section{Conclusion}

Heat stroke is a life-threatening but reversible condition. An intact cardiovascular system is critical for maintenance of thermal homeostasis, and underlying cardiovascular disease, particularly in the elderly, increases risk. Heat stroke results in multiorgan dysfunction, and its cardiovascular complications include arrhythmias, conduction disturbances, myocardial ischemia/injury, and at extremes, heart failure, circulatory collapse, and death. Cooling and supportive care are paramount in management of heat stroke.

Current understanding of the relationship between heat stroke and the cardiovascular system is subject to several limitations, particularly the relative infrequency of major heat waves, and the small and/or retrospective nature of the studies available. As heat waves increase in frequency, further areas of study should explore the efficacy of preventive measures and the role of coronary angiography in patients who have myocardial injury.

\section{Funding Sources}

The authors have no funding sources to declare.

\section{Disclosures}

The authors have no conflicts of interest to disclose.

\section{References}

1. World Weather Attribution. Western North American extreme heat virtually impossible without human-caused climate change. Available at: https://www.worldweatherattribution.org/western-north-american-extremeheat-virtually-impossible-without-human-caused-climate-change. Accessed July 12, 2021.

2. Government of British Columbia. Coroner responded deaths in B.C., June 25-July 1, 2016-2021. Available at: https://www2.gov.bc.ca/gov/ content/life-events/death/coroners-service/news-and-updates/coronerresponded-deaths. Accessed July 15, 2021.

3. Masson Delmotte V, Zhai P, Virani A, et al. IPCC, 2021: Summary for policymakers. In: Climate Change 2021: The Physical Science Basis. Contribution of Working Group I to the Sixth Assessment Report of the
Intergovernmental Panel on Climate Change. Cambridge: Cambridge University Press. October 2021. Available at: https://www.ipcc.ch/report/ ar6/wg1/downloads/report/IPCC_AR6_WGI_SPM_final.pdf. Accessed August 14, 2021.

4. Government of Canada. Temperature change in Canada. Available at: https://www.canada.ca/en/environment-climate-change/services/environmentalindicators/temperature-change.html. Accessed July 15, 2021.

5. Perkins SE, Alexander LV, Nairn JR. Increasing frequency, intensity and duration of observed global heatwaves and warm spells. Geophys Res Lett 2012;39:1-5.

6. Piver WT, Ando M, Ye F, Portier CJ. Temperature and air pollution as risk factors for heat stroke in Tokyo, July and August 1980-1995. Environ Health Perspect 1999;107:911-6.

7. Epstein Y, Yanovich R. Heatstroke. N Engl J Med 2019;380:2449-59.

8. Dehbi M, Baturcam E, Eldali A, et al. Hsp-72, a candidate prognostic indicator of heatstroke. Cell Stress Chaperones 2010;15:593-603.

9. Leon LR, Helwig BG. Heat stroke: role of the systemic inflammatory response. J Appl Physiol 2010;109:1980-8.

10. Bouchama A, Dehbi M, Mohamed G, et al. Prognostic factors in heat wave related deaths: a meta-analysis. Arch Intern Med 2007;167:2170-6.

11. Minson CT, Wladkowski SL, Cardell AF, Pawelczyk JA, Kenney WL. Age alters the cardiovascular response to direct passive heating. J Appl Physiol 1998;84:1323-32.

12. Kenney WL, Morgan AL, Farquhar WB, et al. Decreased active vasodilator sensitivity in aged skin. Am J Physiol 1997;272(4 Pt 2): H1609-14.

13. Berenson GS, Burch GE. The response of patients with congestive heart failure to a rapid elevation in atmospheric temperature and humidity. Am J Med Sci 1952;223:45-53.

14. el-Sherif N, Shahwan L, Sorour AH. The effect of acute thermal stress on general and pulmonary hemodynamics in the cardiac patient. Am Heart J 1970;79:305-17.

15. Tek D, Olshaker JS. Heat illness. Emerg Med Clin North Am 1992;10: 299-310.

16. Akhtar MJ, al-Nozha M, al-Harthi S, Nouh MS. Electrocardiographic abnormalities in patients with heat stroke. Chest 1993;104:411-4.

17. Mimish L. Electrocardiographic findings in heat stroke and exhaustion: a study on Makkah pilgrims. J Saudi Heart Assoc 2012;24:35-9.

18. Bathini T, Thongprayoon C, Petnak T, et al. Circulatory failure among hospitalizations for heatstroke in the United States. Medicines (Basel) 2020;7:32.

19. al-Harthi SS, Nouh MS, al-Arfaj H, et al. Non-invasive evaluation of cardiac abnormalities in heat stroke pilgrims. Int J Cardiol 1992;37: $151-4$.

20. Hausfater P, Doumenc B, Chopin S, et al. Elevation of cardiac troponin I during non-exertional heat-related illnesses in the context of a heatwave. Crit Care 2010;14:R99.

21. Pease S, Bouadma L, Kermarrec N, et al. Early organ dysfunction course, cooling time and outcome in classic heatstroke. Intensive Care Med 2009;35:1454-8.

22. Chen WT, Lin CH, Hsieh MH, Huang CY, Yeh JS. Stress-induced cardiomyopathy caused by heat stroke. Ann Emerg Med 2012;60:63-6.

23. Sprung CL. Hemodynamic alterations of heat stroke in the elderly. Chest 1979;75:362-6. 
24. Dahmash NS, al Harthi SS, Akhtar J. Invasive evaluation of patients with heat stroke. Chest 1993;103:1210-4.

25. Kaiser R, Le Tertre A, Schwartz J, et al. The effect of the 1995 heat wave in Chicago on all-cause and cause-specific mortality. Am J Public Health 2007;97(suppl 1):S158-62.
26. Shapiro Y, Seidman DS. Field and clinical observations of exertional heat stroke patients. Med Sci Sports Exerc 1990;22:6-14.

27. Casa DJ, McDermott BP, Lee EC, et al. Cold water immersion: the gold standard for exertional heatstroke treatment. Exerc Sport Sci Rev 2007;35:141-9. 